CASE REPORT

\title{
Restart the heart
}

\section{Karsten Klingberg, David Srivastava}

Emergency Department, University Hospital Bern, Switzerland

\section{Correspondence to}

Karsten Klingberg, karsten.klingberg@insel.ch

Accepted 16 February 2016

\section{SUMMARY}

Early bystander cardiopulmonary resuscitation and rapid defibrillation are the most important factors for favourable outcomes after out of hospital cardiac arrest (OHCA) - as the new American Heart Association/ European Resuscitation Council (AHA/ERC) guidelines emphasise. The patient in our case was a healthy young man who had a witnessed cardiac arrest due to a chest collision with the goalkeeper during a football match. Basic life support was immediately provided by his teammates until an automated external defibrillator was brought to the scene. Blunt cardiac injury (BCI) may result in injured myocardium or arrhythmias. Ventricular fibrillation due to $\mathrm{BCl}$ in absence of structural cardiac disease is one of the main causes of OHCA in young healthy athletes with high mortality rates. We demonstrate important aspects of the recently released guidelines on cardiac arrest and the chain of survival by the leading societies.

\section{BACKGROUND}

Even an innocent appearing blow to the chest, without damage to the thoracic cage, can lead to sudden cardiac death in otherwise healthy individuals. $^{1-3}$ The mortality caused by nonpenetrating trauma to the anterior chest is either caused by structural injuries to the muscle (Contusio Cordis or Cardiac Contusion) or to electrical disturbances, such as ventricular fibrillation, in the absence of structural cardiovascular injury (Commotio Cordis). ${ }^{4} 5$ The precise incidence of blunt cardiac injury (BCI) is difficult to estimate, though it is reported to be one of the main causes of out of hospital cardiac arrest (OHCA) in young athletes. $^{56}$

To create ventricular fibrillation (VF), two determinants are necessary, first, a blow to the chest directly over the heart and second, that it occurs during the vulnerable phase of repolarisation-a time window of only 10-20 ms during the upstroke of the T wave just before its peak. ${ }^{7}$ Survival rates after BCI were relatively low, around $20 \%,{ }^{8}{ }^{9}$ in the past, but have recently been improving due to the promotion of early cardiopulmonary resuscitation (CPR) and defibrillation. ${ }^{45}$

\section{CASE PRESENTATION}

A 21-year-old previously healthy man was brought in by helicopter to our resuscitation bay. The patient
To cite: Klingberg $\mathrm{K}$ Srivastava D. BMJ Case Rep Published online: [please include Day Month Year] doi:10.1136/bcr-2016214382
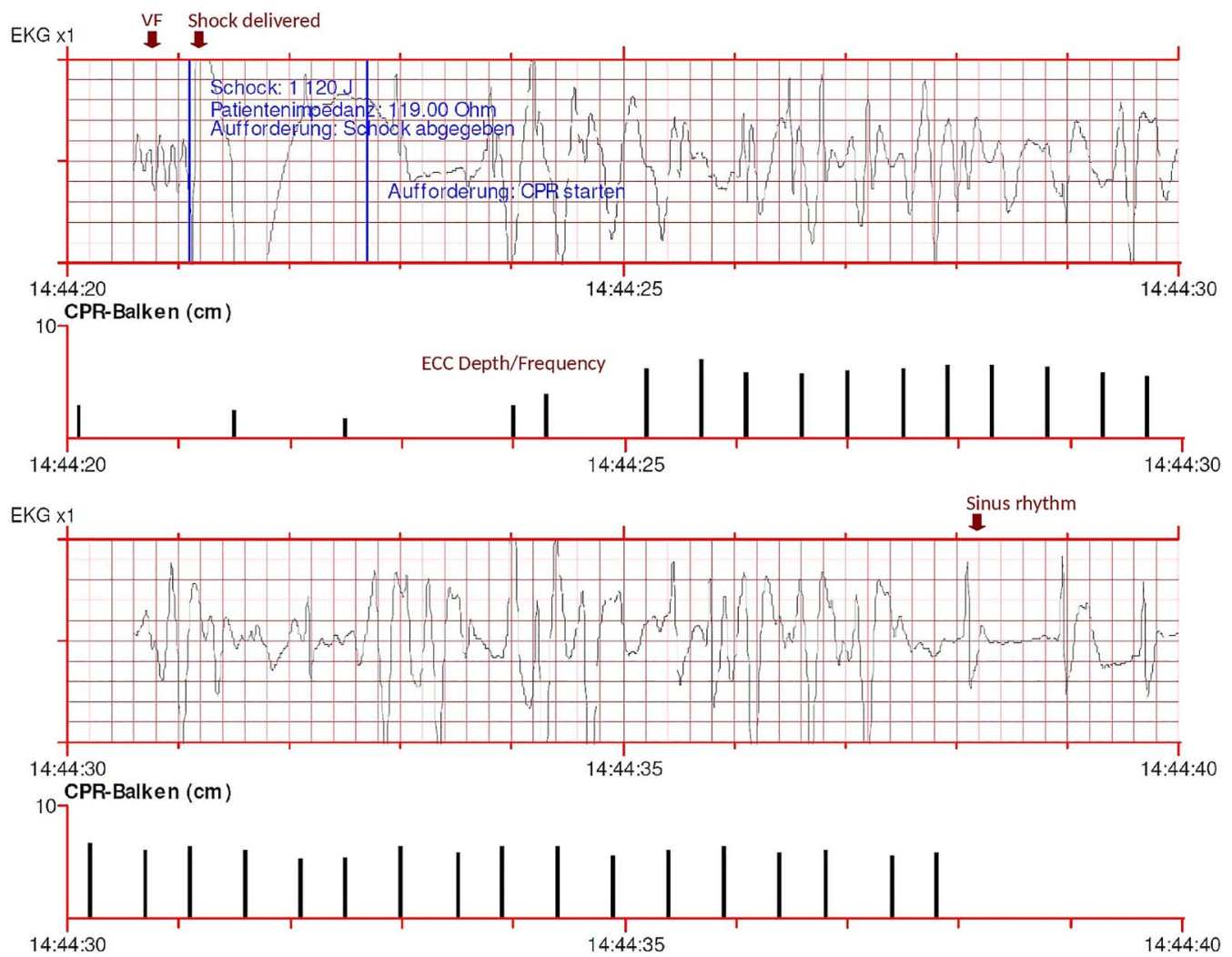

Figure 1 AED report. AED, automated external defibrillator; VF, ventricular fibrillation. 


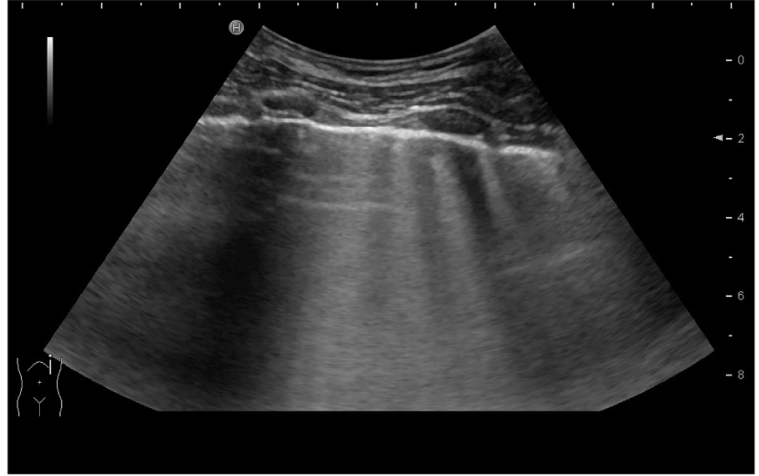

Figure 2 POCUS showing B-lines. POCUS, point of care ultrasound.

had suffered from a blunt trauma to the chest from the goalkeeper's shoulder during a football match.

After the impact, the patient took a few steps before he collapsed on the pitch. The hurrying teammates (partly basic life support (BLS) trained) did not notice any signs of life and began immediate resuscitation with external chest compressions (ECC) until an automated external defibrillator (AED) was brought to the scene. The AED detected VF and one shock was immediately delivered, as the report, provided later by the manufacturer, shows (figure 1). Following the defibrillation, the patient had a return of spontaneous circulation (ROSC) with neurological recovery to Glasgow Coma Scale (GCS) 14-15, supported by only one dose of $20 \mu \mathrm{g}$ epinephrine during transport.

On arrival, the patient had a free airway with slight epistaxis, but no other signs of head injury. Lungs were ventilated with rales on both sides and oxygen saturation was $93 \%$ with highflow oxygen.

The thorax was stable with painful palpation on the right side. Pulses were symmetric and strong without signs of circulatory compromise.

The patient was alert and oriented without any neurological deficits.

Blood pressure was $125 / 70 \mathrm{~mm} \mathrm{Hg}$ with a heart rate of 100 / $\min$.

\section{INVESTIGATIONS}

After Primary Survey, a point of care ultrasound (POCUS) demonstrated no pathologies other than signs of a pulmonary interstitial syndrome (B-lines, figure 2). ${ }^{10}$ The initial ECG was judged normal. Early transthoracic echocardiography (TTE) in the resuscitation bay revealed a structural normal heart without any traumatic damage and initial troponin (high-sensitive) remained negative.

As the patient showed signs of lung injury with low oxygen saturation, pathological ultrasound and the development of haemoptysis during the Secondary Survey, a CT scan of the thorax was performed. The scan showed bilateral haemorrhage (figure 3) accompanied by a non-displaced sternal fracture (figure 4).

\section{DIFFERENTIAL DIAGNOSIS}

Severe structural cardiovascular damage seemed unlikely, as patients with major injuries often die at the scene. ${ }^{11}$

Other reversible causes such as tension pneumothorax, haemorrhagic shock or pericardial tamponade were quickly excluded by POCUS.

Less likely causes such as hypoxia, hyper-/hypokalaemia and hypothermia were also excluded.

The CT scan showed no pulmonary embolism and no injury of the intrathoracic vessels.

As recommended by EAST (Eastern Association for the Surgery of Trauma) in 2012, an ECG and troponin measurement are the minimum requirements to prove the diagnosis of BCI with a negative predictive value from almost $100 \% .^{12}$

In our case, troponin peaked $6 \mathrm{~h}$ after presentation, to $0067 \mu \mathrm{g} / \mathrm{L}$ (normal range $<0.014$ ).

$\mathrm{VF}$ as the cause of the cardiac arrest due to BCI was strongly suspected but not confirmed until we received the report of the AED by the manufacturer later (figure 1). The report showed $\mathrm{VF}$ with one shock given and the return of a regular sinus rhythm with small QRS complexes-presenting as ROSC after a total of about $10 \mathrm{~min}$ BLS efforts.

Note that this model of AED (Zoll AED Plus) also measures depth and frequency of chest compressions and can be used for retrospective quality control of delivered CPR (figure 1).

\section{TREATMENT}

Bi-pulmonary haemorrhage presenting with haemoptysis was treated with tranexamic acid $1 \mathrm{~g}$ intravenously and inhalation of xylometazoline $1 \mathrm{mg}$ in $3 \mathrm{~mL}$ saline. In this case, no further treatment or intervention was needed after ROSC, as the patient's vital signs remained stable and no ischaemic cause for the cardiac arrest was suspected.
Figure 3 CT scan showing

bi-pulmonary haemorrhage.

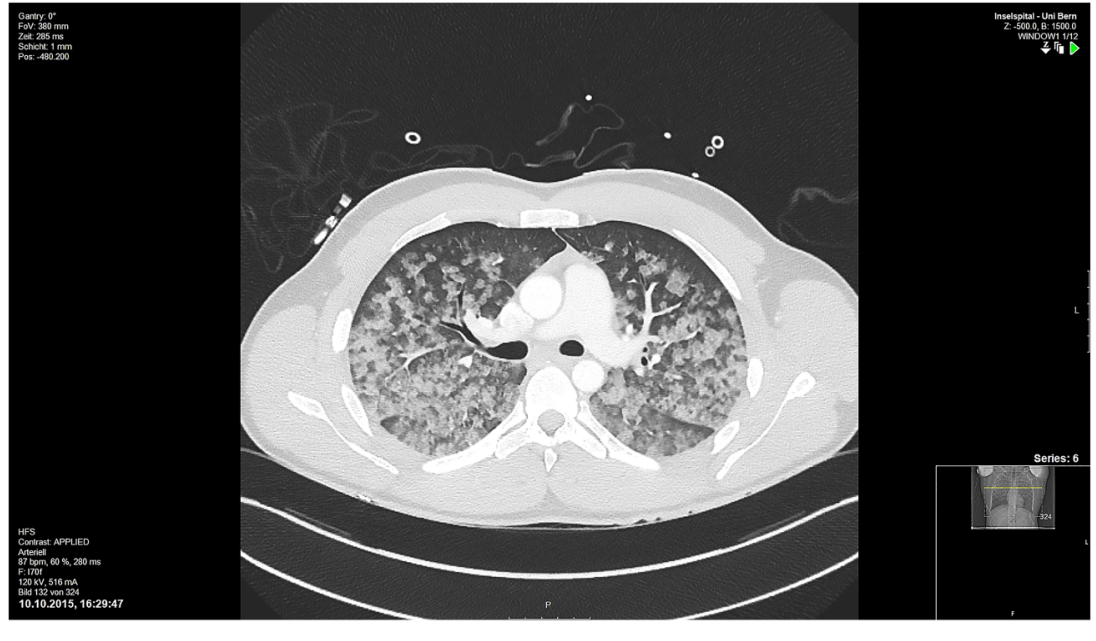

Klingberg K, Srivastava D. BMJ Case Rep 2016. doi:10.1136/bcr-2016-214382 
Figure 4 CT sagittal view showing non-dislocated sternal fracture.

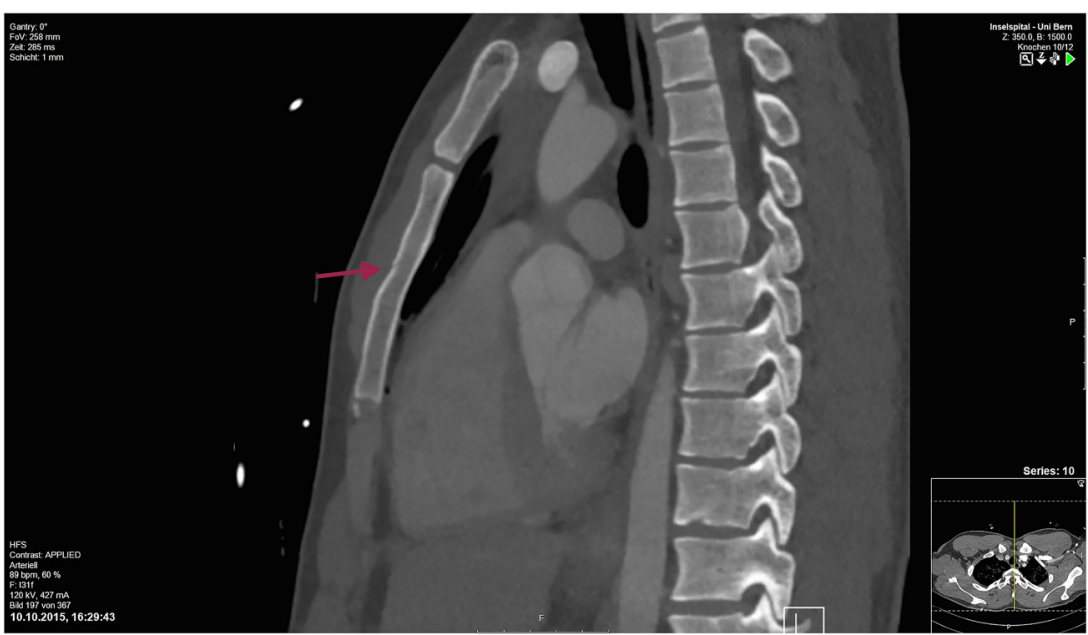

\section{OUTCOME AND FOLLOW-UP}

The patient was sent to ICU for further monitoring of ventilation and haemodynamics. He underwent extensive diagnostic tests including sequential ECG, coronary angiography, heart MRI and TTE. All the tests were normal and there was no indication for implantation of an Iimplantable cardioverter defibrillator (ICD). No restriction against competitive sports was given as no cardiovascular abnormality was identified.

The patient recovered well and is playing football again. He was very thankful towards his teammates who saved his life.

\section{DISCUSSION}

Early bystander CPR and early defibrillation with public accessed AEDs are the most important actions for good outcomes in OHCA, as there is a direct correlation between beginning and quality of CPR, time to defibrillation and survival. ${ }^{3} 13$

The assessment of patient with OHCA demands early exclusion of reversible causes, better known as the 4 H's (Hypoxia, Hypovolaemia, Hypo-/hyperkalaemia/metabolic, Hypo-/hyperthermia and 4 T's (Thrombosis - coronary or pulmonary, Tension pneumothorax, Tamponade - cardiac, Toxins). ${ }^{1} 2$ Pretest probabilities depend on circumstances and the patient's medical history.

POCUS in the ED or, if available, in prehospital settings, is an important diagnostic tool in traumatic cardiac arrest and can be integrated unobtrusively into resuscitation protocols. ${ }^{14}$

The rapid diagnosis of occult haemorrhage, tension pneumothorax or cardiac tamponade with POCUS has shown to reduce time to treatment in trauma patients. ${ }^{14}$

\section{Learning points}

Even a harmless appearing chest trauma can, if directed over the heart and during the electrically vulnerable phase, lead to ventricular fibrillation.

- Early cardiopulmonary resuscitation by basic life support-trained bystanders is paramount and improves the outcome in out of hospital cardiac arrest, and even more so after blunt cardiac injury $(\mathrm{BCl})$ without structural damage of the heart.

- Public access automated external defibrillator (AED) programmes should be actively implemented in public places and sport areas where $\mathrm{BCl}$ is likely to occur.

- Review of the AED's log can help to confirm diagnosis and can be used as a quality control tool.
The witnesses in this case described that the athlete walked a few steps after the impact before collapsing on the field. This corresponds with the current literature where athletes suffering from BCI are described to stay conscious for a short period after impact. ${ }^{9} 15$

Even if sternal fractures raise the suspicion for BCI, studies so far have failed to show a direct correlation. ${ }^{12} 16$

In our patient, we believe the injury was caused by ECCs. ${ }^{17}$

Acknowledgements The authors thank the AED manufacturer ZOLL, their Radiology Department and Beat Lehmann and Prof. A. Exadaktylos for their support. Competing interests None declared.

\section{Patient consent Obtained.}

Provenance and peer review Not commissioned; externally peer reviewed.

\section{REFERENCES}

1 Monsieurs KG, Nolan JP, Bossaert LL, et al. European resuscitation council guidelines for resuscitation 2015: section 1. Executive summary. Resuscitation 2015;95:1-80.

2 Neumar RW, Shuster M, Callaway CW, et al. Part 1: Executive summary: 2015 American Heart Association guidelines update for cardiopulmonary resuscitation and emergency cardiovascular care. Circulation 2015;132(18 suppl 2):S315-67.

3 Weisfeldt ML, Sitlani CM, Ornato JP, et al. Survival after application of automatic external defibrillators before arrival of the emergency medical system: evaluation in the resuscitation outcomes consortium population of 21 million. J Am Coll Cardiol 2010;55:1713-20.

4 Yousef R, Carr JA. Blunt cardiac trauma: a review of the current knowledge and management. Ann Thorac Surg 2014;98:1134-40.

5 Maron BJ, Estes NA III. Commotio cordis. N Engl J Med 2010;362:917-27.

6 Brewer B, Zarzaur B. Cardiac contusions. Curr Trauma Rep 2015;1:232-6.

7 El-Chami MF, Nicholson W, Helmy T. Blunt cardiac trauma. J Emerg Med 2008;35:127-33

8 Maron BJ, Gohman TE, Kyle SB, et al. Clinical profile and spectrum of commotio cordis. JAMA 2002;287:1142-6.

9 Maron BJ, Poliac LC, Kaplan JA, et al. Blunt impact to the chest leading to sudden death from cardiac arrest during sports activities. N Engl J Med 1995;333: 337-42.

10 Zechner PM, Seibel A, Aichinger G, et al. Lungensonographie in der Akut-und Intensivmedizin. Anaesthesist 2012;61:608-17

11 Turan AA, Karayel FA, Akyildiz E, et al. Cardiac injuries caused by blunt trauma: an autopsy based assessment of the injury pattern. J Forensic Sci 2010;55:82-4

12 Clancy K, Velopulos C, Bilaniuk JW, et al. Screening for blunt cardiac injury: An Eastern Association for the Surgery of Trauma practice management guideline. J Trauma Acute Care Surg 2012;73:S301-6.

13 Hasselqvist-Ax I, Riva G, Herlitz J, et al. Early cardiopulmonary resuscitation in out-of-hospital cardiac arrest. N Engl J Med 2015;372:2307-15.

14 Smith JE, Le Clerc S, Hunt PA. Challenging the dogma of traumatic cardiac arrest management: a military perspective. Emerg Med J 2015;32:955-60.

15 Maron BJ. Sudden death in young athletes. N Engl J Med 2003;349:1064-75.

16 Skinner $\mathrm{DL}$, Laing $\mathrm{GL}$, Rodseth $\mathrm{RN}$, et al. Blunt cardiac injury in critically ill trauma patients: a single centre experience. Injury 2015;46:66-70.

17 Hoke RS, Chamberlain D. Skeletal chest injuries secondary to cardiopulmonary resuscitation. Resuscitation 2004;63:327-38. 
Copyright 2016 BMJ Publishing Group. All rights reserved. For permission to reuse any of this content visit http://group.bmj.com/group/rights-licensing/permissions.

BMJ Case Report Fellows may re-use this article for personal use and teaching without any further permission.

Become a Fellow of BMJ Case Reports today and you can:

- Submit as many cases as you like

- Enjoy fast sympathetic peer review and rapid publication of accepted articles

- Access all the published articles

- Re-use any of the published material for personal use and teaching without further permission

For information on Institutional Fellowships contact consortiasales@bmjgroup.com

Visit casereports.bmj.com for more articles like this and to become a Fellow 